\title{
Assessment of the Knowledge and Attitude Towards Dementia Among Undergraduate University Students in Uganda
}

\author{
Phillip Musoke $\mathbb{D}^{\prime}$ \\ Ronald Olum (D) \\ Shallon Kembabazi ${ }^{1}$ \\ Brandy Nantaayi (1D' \\ Felix Bongomin (1D) ${ }^{2}$ \\ Mark Kaddumukasa $\mathbb{( D D}^{3}$ \\ 'School of Medicine, College of Health \\ Sciences, Makerere University, Kampala, \\ Uganda; ${ }^{2}$ Department of Medical \\ Microbiology and Immunology, Faculty of \\ Medicine, Gulu University, Gulu, Uganda; \\ ${ }^{3}$ Department of Medicine, School of \\ Medicine, College of Health Sciences, \\ Makerere University, Kampala, Uganda
}

Correspondence: Phillip Musoke School of Medicine, College of Health Sciences, Makerere University, Kampala, Uganda

Email musokephillipneffsize@gmail.com
Background: Dementia remains a public health concern and a leading cause of disability and dependency among older people worldwide. However, the knowledge and attitudes towards dementia among university students remain unknown. This study assessed the knowledge and attitude towards dementia among university students in Uganda.

Methods: An online descriptive, cross-sectional study was undertaken from August to November 2020, among undergraduate students from 11 Ugandan universities. A validated study questionnaire was used to collect data on socio-demographic characteristics, knowledge, and attitudes of dementia. A score $<60 \%$ was considered poor knowledge while $\geq 80 \%$ good knowledge and more than $80 \%$ reflected positive attitudes.

Results: Overall, 1005 participants with a median age of 23 (interquartile range: 18 to 35) years participated in the study. The majority of the students were male $(56.5 \%, \mathrm{n}=568)$ and nearly half were pursuing human sciences/medicine-related programs. The mean knowledge score was $65.5 \%(\mathrm{SD} \pm 18.5)$. Thirty-two percent of the study participants had poor knowledge and only $26.8 \%(n=269)$ had good knowledge of dementia. More than half of the study participants believed that dementia is a normal part of aging and that memory loss happens to all people as they age. Attitudes towards patients with dementia were positive with a mean score of $81.9 \%(\mathrm{SD} \pm 19.6)$ and $65.2 \%$ of the study participants had positive dementia attitudes. Those aged more than 24 years were significantly associated with positive attitudes (adjusted odds ratio (AOR): 1.5, 95\% CI: 1.1-2.0, $\mathrm{p}=0.019$ ). There was a weak correlation between knowledge and attitude scores $(\rho=0.341, \mathrm{p}<0.001)$.

Conclusion: Whereas the majority of university students have positive attitudes towards patients with dementia, a significant number still have poor knowledge of the same. Continuous health education is suggested to improve knowledge of dementia in this population. Further studies to understand the perception in the general population are recommended.

Keywords: dementia, Alzheimer's disease, knowledge, attitude, Uganda

\section{Introduction}

Dementia is a public health concern and a leading cause of disability and dependency among people of old age worldwide. ${ }^{1}$ Globally, about 10 million people develop dementia each year, and nearly $60 \%$ of these estimates reside in low- and middle-income countries (LMICs). ${ }^{2}$ About 2.13 million people are estimated to be living with dementia in Sub-Saharan Africa (SSA), with the majority contributed by Alzheimer's disease (AD). Dementia in SSA is projected to surpass 3.48 million by $2030 .^{3}$ The elderly population in Uganda is projected to reach $5,420,000$ by $2050 .^{4}$ 
Therefore, the increasing elderly population coupled with the high prevalence of dementia at $20 \%$ justifies studies to understand the attitudes and knowledge within the general population. $^{5}$

Dementia can be overwhelming, not only for the patients but also their caregivers and immediate families. Often, there is a lack of awareness and limited understanding of dementia, resulting in stigmatization, discrimination, social exclusion, barriers to diagnosis and care with the associated physical, psychological, social, and economic burden on caregivers, family, and society. ${ }^{1,6}$

Studies have found poor knowledge and understanding of dementia amongst the general population as well as the caregivers of individuals with dementia ${ }^{7,8}$ especially within SSA. ${ }^{9}$ The poor knowledge and attitudes towards dementia may be leading to delayed health-seeking behaviors and lifestyle changes that might impact the condition progression.

Presently, no study in Uganda has assessed the knowledge and attitude of the general population towards dementia. University students form part of the general population and play an important role in information dissemination and provision of care to dementia patients within communities. Therefore, this study set out to determine the knowledge and attitudes of university students towards dementia in Uganda.

\section{Methods and Materials Study Design and Area}

An online descriptive, cross-sectional study, was undertaken from August to November 2020. Undergraduate students from 11 universities, both private and public universities were included;

Public universities: Makerere University, Mbarara University of Science and Technology, Kyambogo University, Gulu University, and Busitema University.

Private universities: Kampala International University (KIU), Uganda Christian University (UCU), Islamic University in Uganda (IUIU), St. Augustine (King Caesar) International University, and Ndejje University. There are currently, 32 universities in Uganda all accounting for a student population of about 110,000, turning out over 30,000 graduates annually. Makerere University alone accounts for over $30 \%$ of this total and the majority of these come from all over the country. (https://www. ubos.org/wp-content/uploads/publications/11-2020).

\section{Selection Criteria}

Students aged 18 years and above, enrolled in one of the above universities were included in the study after informed electronic consent.

\section{Sample Size and Sampling}

The sample size was calculated using Epi Info StatCalc for population surveys. With an estimated population size of university students in Uganda at 60,000, expected average knowledge at $53.4 \%$ according to the study in South Africa, ${ }^{10} 3 \%$ acceptable margin of error and design effect of 1 , the estimated sample size at $95 \%$ confidence interval was therefore, 1044 students.

\section{Data Collection Procedure}

Students identified through the guild presidents of the different universities, student federations, student associations, and class WhatsApp groups received a link to a detailed study Google form questionnaire containing 40 questions and a consent form. This was shared via social media platforms (WhatsApp Messenger and Facebook Inc. California, USA).

\section{Questionnaire Development}

The study questionnaire was adapted from a pre-existing validated questionnaire which was used in South Africa, Khayelitsha for isiXhosa-speaking people. ${ }^{10}$ The questionnaire consisted of closed and open-ended questions and was divided into 4 sections: socio-demographics-age, sex, region of origin, religion, tribe, marital status, universityaffiliated to, program and year of study, if they have heard or know someone who has dementia, knowledge of dementia, a self-rated knowledge scale, and attitudes towards dementia.

\section{Assessments \\ Knowledge of Dementia}

Sixteen (16) items obtained from Khonje et al, were used to assess dementia knowledge. ${ }^{10}$ The total knowledge score was calculated by adding the correct responses to produce a score that ranges from 0 to 16 ; ( 1 mark was awarded for every correct response and zero marks were given for incorrect response). The total knowledge score for each participant out of 16 was calculated, which was then converted to a percentage. The Cronbach alpha score for the 16 items was 0.70 , implying acceptable internal reliability of the scale. Furthermore, respondents were 
asked to self-rate their level of knowledge of dementia based on a scale of 0 to 10 (score of 0 if "I know nothing at all" to 10 , if "I am very knowledgeable").

\section{Attitude Toward Patients with Dementia}

Eight (8) questions acquired from Khonje et al, were used to assess dementia attitude. ${ }^{10}$ The total attitude score was calculated by adding the positive responses to produce a score that ranges from 0 to 8 ( 1 mark was awarded for every positive response and zero marks were given for negative response). The attitude score was then converted to percentages. For the attitude scale, the Cronbach alpha score was 0.71 indicating acceptable internal reliability.

\section{Data Analysis and Management}

Fully completed questionnaires were extracted from the google form and exported to a Microsoft Excel 2016 for cleaning and coding. The cleaned data was exported to STATA 16 (StataCorp LLC, College Station, Texas, USA) for analysis. Numerical data were then summarized as means and standard deviations or median and range as appropriate for parametric or non-parametric conditions as assessed using the Shapiro-Wilk test. Categorical data were summarized as frequencies and proportions. Bloom's cut-off of $80 \%$ was used to determine sufficient knowledge $(\geq 80 \%)$ and positive attitude $(\geq 4) .{ }^{11}$ Associations between independent variables (age, education details, tribe, ethnicity, sex, course of study, year of study, and sources of information on dementia) and dependent variables (level of knowledge and attitude towards dementia) were assessed at bivariate analysis using chi-square or Fisher's Exact test. Variables with a $\mathrm{P}<0.2$ were fitted into a multivariable logistic regression model to adjust for confounders. A $\mathrm{P}<0.05$ was considered statistically significant for all hypothesis testing.

\section{Covid-19 Safety Precautions}

The study was conducted following the Ministry of health and the national covid-19 task force guidelines of Uganda. All the study team meetings, training, recruitment, data collection, and manuscript drafting were conducted online.

\section{Results}

\section{Characteristics of Participants}

A total of 1008 students responded to the survey (response rate $=97 \%$ ). After removing 3 incomplete responses, data of 1005 students were analyzed. The median age of the respondents was 23 (interquartile range: 18 to 38 ) years.
About $56.5 \%$ were males and only $5 \%(\mathrm{n}=60)$ were in their fifth year of study. Over $90 \%$ of the students were single and were Christians (84.1\%). Nearly half of the respondents were pursuing human sciences or medicinerelated programs $(46.8 \%, n=470)$ and nearly half $(49.3 \%$, $\mathrm{n}=495$ ) were from Makerere University, the largest public tertiary institution in Uganda. Table 1 summarizes the socio-demographic characteristics of the participants.

\section{Awareness and Knowledge of Dementia}

About $78 \%(\mathrm{n}=785)$ of the participants had heard about dementia or Alzheimer's disease. Table 2 summarizes the responses of participants to questions on knowledge. Up to $53.4 \%$ believed that memory loss happened to all people as they age. However, the majority disagreed that forgetting family members (72\%), names of objects $(63 \%)$, and having trouble with speaking or understanding (53\%) were normal parts of aging in humans. Remarkably, $60.2 \%$ of the participants were able to identify that the above symptoms were for dementia. Only $2.0 \%$ and $1.3 \%$ thought dementia was a punishment from God or ancestors, respectively. About $15.8 \%$ of the participants believed dementia affects only elderly people. Overall, nearly half had moderate knowledge $(\mathrm{n}=410,41 \%)$ on dementia with only $26.8 \%$ having good knowledge and $32 \%$ had poor knowledge (Figure 1). This correlated with self-rated knowledge scale (no knowledge $=5 \%$, poor knowledge $=40 \%$, moderate knowledge $=43 \%$, very knowledgeable $=13 \%$ ).

At bivariate analysis (Table 3), good knowledge was associated with age $(p=0.009)$, year of study $(p<0.0001)$, academic program $(p<0.0001)$, region of origin $(p<0.0001)$ and university $(\mathrm{p}<0.0001)$. At multivariable logistic regression (Table 4), third - (AOR: 1.8, 95\% CI: 1.0-3.2, $\mathrm{p}=0.035$ ), fourth- (AOR: 3.1, 95\% CI: 1.7-5.4, $\mathrm{p}<0.0001$ ), and fifth-year students (AOR: 4.3, 95\% CI: 2.0-9.4, $\mathrm{p}<0.0001)$ significantly had higher knowledge of dementia. Students pursuing human science or medicine-related programs were thrice more likely to have good knowledge of dementia (AOR: 3.1, 95\% CI: 1.2-8.0, $\mathrm{p}=0.017$ ). Also, students from eastern (AOR: 0.5, 95\% CI: 0.3-0.8, $\mathrm{p}=0.002$ ), northern (AOR: 0.3, 95\% CI: $0.1-0.5$, $\mathrm{p}<0.0001)$ and western Uganda (AOR: $0.5,95 \%$ CI: $0.4-$ $0.8, \mathrm{p}=0.001$ ) were less likely to have good knowledge of dementia compared to those in central Uganda.

\section{Attitudes Toward Dementia}

Table 5 describes the attitudes of university students towards patients with dementia. The vast majority of the participants 
Table I Social and Demographic Characteristics of Participants

\begin{tabular}{|c|c|c|}
\hline Demographics $(N=\mid 005)$ & $\begin{array}{l}\text { Frequency } \\
\text { (n) }\end{array}$ & $\%$ \\
\hline \multicolumn{3}{|l|}{ Sex } \\
\hline Male & 568 & 56.5 \\
\hline Female & 437 & 43.5 \\
\hline \multicolumn{3}{|l|}{ Year of study } \\
\hline 1 & 146 & 14.5 \\
\hline 2 & 234 & 23.3 \\
\hline 3 & 280 & 27.9 \\
\hline 4 & 285 & 28.4 \\
\hline 5 & 60 & 6.0 \\
\hline \multicolumn{3}{|l|}{ Program } \\
\hline Agriculture and environment Sciences & 34 & 3.4 \\
\hline Business and management sciences & 96 & 9.6 \\
\hline Computer and information science & 56 & 5.6 \\
\hline Education and external studies & 42 & 4.2 \\
\hline Engineering, designing art and technology & 164 & 16.3 \\
\hline Human Sciences/ Medicine & 470 & 46.8 \\
\hline Humanities and social Sciences & 49 & 4.9 \\
\hline Law & 57 & 5.7 \\
\hline Veterinary medicine, animal resources. & 37 & 3.7 \\
\hline \multicolumn{3}{|l|}{ Region of origin } \\
\hline Western & 368 & 36.6 \\
\hline Central & 345 & 34.3 \\
\hline Eastern & 202 & 20.1 \\
\hline Northern & 90 & 9.0 \\
\hline \multicolumn{3}{|l|}{ Religion } \\
\hline Christianity & 845 & 84.1 \\
\hline Islam & 136 & 13.5 \\
\hline No religion & 18 & 1.8 \\
\hline Traditional African & 6 & 0.6 \\
\hline \multicolumn{3}{|l|}{ Marital status } \\
\hline Single (never married) & 913 & 90.9 \\
\hline Married & 55 & 5.5 \\
\hline Cohabiting & 34 & 3.4 \\
\hline Divorced and did not remarry & 3 & 0.3 \\
\hline \multicolumn{3}{|l|}{ University } \\
\hline Makerere University & 495 & 49.3 \\
\hline Mbarara University of Science and Technology & 90 & 9.0 \\
\hline Uganda Christian University & 85 & 8.5 \\
\hline Kyambogo University & 83 & 8.3 \\
\hline Kampala International University & 78 & 7.8 \\
\hline Islamic University in Uganda & 53 & 5.3 \\
\hline Busitema University & 50 & 5.0 \\
\hline Gulu University & 30 & 3.0 \\
\hline Ndejje University & 25 & 2.5 \\
\hline St. Augustine International University & 12 & 1.2 \\
\hline Uganda Martyrs University & 4 & 0.4 \\
\hline
\end{tabular}

Abbreviations: $n$, number of participants; \%, proportion of participants. were not scared to have as a neighbor $(86.8 \%)$ as well sharing a house $(88.5 \%)$ with a person with dementia. Only a few participants believed that persons with dementia were responsible for the condition (5.6\%) and are dangerous people who should be avoided (7.2\%). Overall, about twothirds $(65 \%, n=655)$ of the students had a positive attitude towards persons with dementia (Figure 2). At bivariate analysis, age $(\mathrm{p}<0.0001)$, year of study $(\mathrm{p}=0.041)$, and academic program $(p=0.006)$ were associated with a positive attitude towards persons with dementia (Table 6).

University students aged 24 years and above were 1.5 times more likely to have a positive attitude towards persons with dementia at multivariable logistic regression (AOR: 1.5, 95\% CI: 1.1-2.0, $\mathrm{p}=0.019$, Table 7).

When pairwise correlation was performed, there was a weak correlation between knowledge and attitude scores $(\rho=0.341, \mathrm{P}<0.001)$.

\section{Discussion}

In this study, we administered an online questionnaire to undergraduate students to determine their attitudes and knowledge of dementia. The present study contributes information that would help refocus curricula for both medical and non-medical undergraduate students as well as guide targeted interventions to raise awareness of dementia in the general population. This study found that only $26.8 \%$ of the study participants had good knowledge regarding dementia and two-thirds had a good attitude regarding dementia.

Overall, the mean knowledge score on dementia of $65.5 \%$ was higher compared to that of the Norwegian undergraduate health and social care students of $23.51 \%{ }^{12}$ and the undergraduate students of the University of Kathmandu who had $51.5 \%$ score. ${ }^{13}$ This may be due to fact that we used a different study questionnaire and scoring tool to what was used in these studies in Norway and Kathmandu, Nepal. This might explain the difference in scores. We adapted a pre-existing validated questionnaire that was used among the Xhosa-speaking people in South Africa while the other studies utilized the validated version of the Alzheimer's disease Knowledge Scale (ADKS).

Furthermore, the mean knowledge score obtained in this study was higher compared to $53.44 \%$ found among the Urban Xhosa-Speaking Community in South Africa. ${ }^{10}$ The South African study was the closest we could compare our study with, due to the lack of similar studies in Sub-Saharan Africa and Africa in general. The two studies, however, were conducted in different target populations; undergraduate students 
Table 2 Responses of Participants to Questions About Knowledge on Alzheimer's Disease and Dementia

\begin{tabular}{|c|c|c|c|}
\hline Questions ( $N=1005)$ & $\begin{array}{l}\text { Yes; } \\
\text { n (\%) }\end{array}$ & $\begin{array}{l}\text { No; } \\
\text { n (\%) }\end{array}$ & $\begin{array}{l}\text { I Do Not Know; } \\
\text { n (\%) }\end{array}$ \\
\hline Does memory loss happen to all people as they get older? * & $537(53.4)$ & $342(34)$ & $126(12.5)$ \\
\hline Is forgetting who your family members are a normal part of getting old? * & $167(16.6)$ & $724(72)$ & $114(11.3)$ \\
\hline Is forgetting the names of objects a normal part of getting old? * & $273(27.2)$ & $633(63)$ & $999(99.4)$ \\
\hline Is having trouble with speaking or understanding a normal part of getting old? * & $373(37.1)$ & $529(52.6)$ & $103(10.2)$ \\
\hline $\begin{array}{l}\text { The above symptoms form part of a medical condition, what would you call this medical condition? } \\
\text { (correct, wrong, I do not know) * }\end{array}$ & $605(60.2)$ & $167(16.6)$ & $233(23.2)$ \\
\hline Do you think dementia is normal? * & $177(17.6)$ & $709(70.5)$ & $119(11.8)$ \\
\hline Do you think dementia is contagious? $*$ & $5 I(5.1)$ & $846(84.2)$ & $108(10.7)$ \\
\hline Do you think poverty can cause dementia? & $285(28.4)$ & $611(60.8)$ & $109(10.8)$ \\
\hline Do you think a brain disease can be the cause of dementia? $*$ & $874(87)$ & $43(4.3)$ & $88(8.8)$ \\
\hline Do you think dementia is a punishment from God? & $20(2.0)$ & $912(90.7)$ & $73(7.3)$ \\
\hline Do you think dementia is a punishment from ancestors? & $13(1.3)$ & $936(93.1)$ & $56(5.6)$ \\
\hline Do you think dementia can run in families? $*$ & $644(64.1)$ & $221(22)$ & $140(13.9)$ \\
\hline Do you think a traumatic event or shock can result in dementia? * & $849(84.5)$ & $63(6.3)$ & $93(9.3)$ \\
\hline Do you think stress in daily life can cause dementia? $*$ & $769(76.5)$ & $126(12.5)$ & $110(10.9)$ \\
\hline Do you think dementia is only a disease that affects older people? * & $159(15.8)$ & $778(77.4)$ & $68(6.8)$ \\
\hline Do you think women are more likely to get dementia than men? * & $212(21.1)$ & $409(40.7)$ & $384(38.2)$ \\
\hline Do you think there is a cure for dementia? * & $307(30.5)$ & $414(4 \mid .2)$ & $284(28.3)$ \\
\hline Do you think people with dementia have mental and physical problems? * & $691(68.8)$ & $198(19.7)$ & $116(11.5)$ \\
\hline Do you think people with dementia are mad? * & $29(2.9)$ & $915(91)$ & $61(6.1)$ \\
\hline Do you think traditional healers can heal people with dementia? & $32(3.2)$ & $845(84.1)$ & $128(12.7)$ \\
\hline Do you believe dementia is a curse or witchcraft? & $15(1.5)$ & $916(91.1)$ & $74(7.4)$ \\
\hline
\end{tabular}

Notes: *The 16 items were used for calculating knowledge score with a total of 16 points; $n$ denotes number of participants, $\%$ denotes proportion of participants.

versus the Urban Xhosa-Speaking people. Our study population included students undertaking various health programs hence more likely to have interfaced/interacted with a dementia patient/family. Also, campaigns to increase dementia knowledge within the general population are ongoing within Uganda.

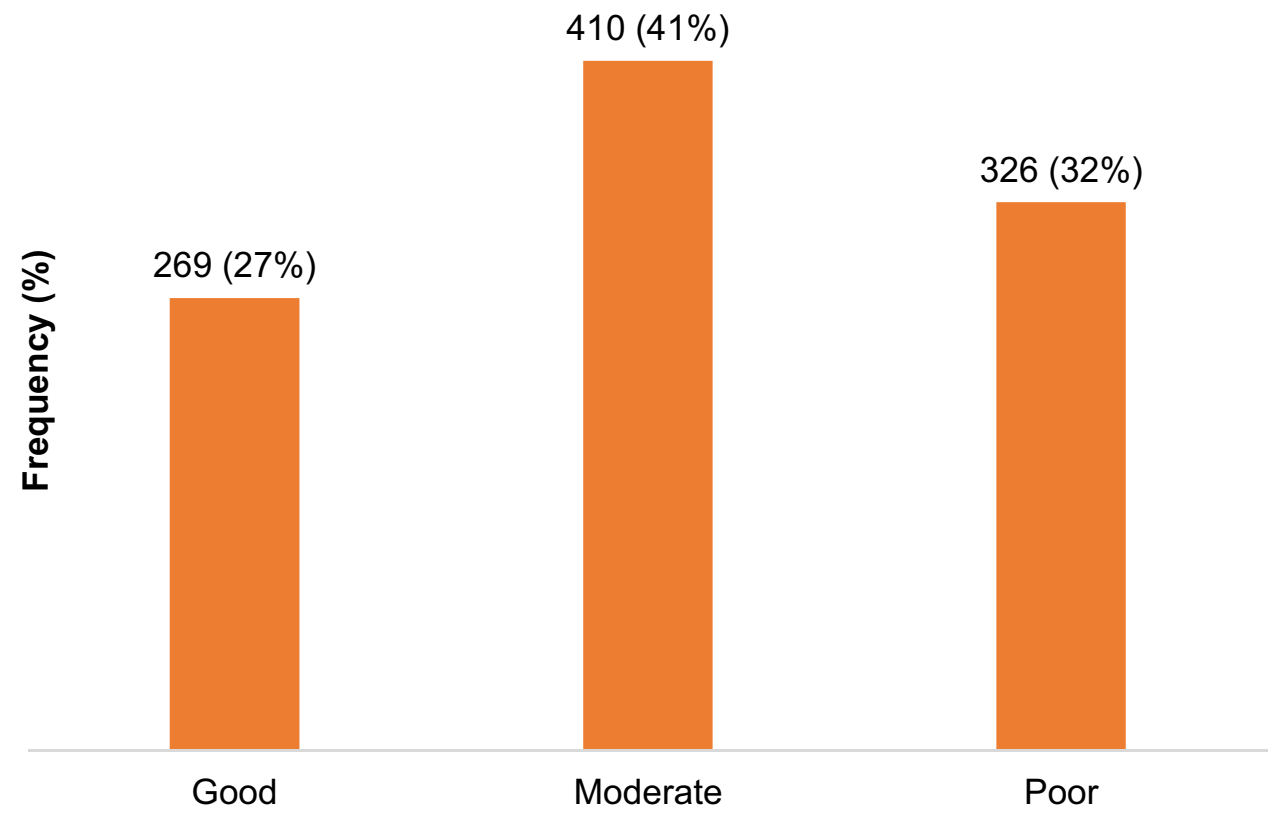

Knowledge on dementia

Figure I Categories of knowledge on dementia among Ugandan university students. 
Table 3 Factors Associated with Good Knowledge of Dementia Among Ugandan University Students

\begin{tabular}{|c|c|c|c|c|c|}
\hline \multirow[t]{2}{*}{ Demographics $(N=1005)$} & \multicolumn{2}{|c|}{ Knowledge Score } & \multicolumn{3}{|c|}{ Good Knowledge } \\
\hline & Mean & SD & Yes & No & P-value \\
\hline Overall & 65.5 & 18.5 & $269(26.8)$ & $736(73.2)$ & \\
\hline \multicolumn{6}{|l|}{ Sex } \\
\hline Male & 65.3 & 18.7 & $145(25.5)$ & $423(74.5)$ & 0.312 \\
\hline Female & 65.8 & 18.3 & $124(28.4)$ & $313(7 \mid .6)$ & \\
\hline \multicolumn{6}{|l|}{ Age; median, IQR } \\
\hline$<23$ & 64.0 & 18.3 & I54 (24) & $487(76)$ & 0.009 \\
\hline$\geq 24$ & 68.1 & 18.6 & $115(31.6)$ & $249(68.4)$ & \\
\hline \multicolumn{6}{|l|}{ Year of study } \\
\hline I & 61.8 & 19.4 & $26(17.8)$ & $120(82.2)$ & $<0.001$ \\
\hline 2 & 62.6 & 16.7 & $43(18.4)$ & $191(81.6)$ & \\
\hline 3 & 64.3 & 18.7 & $69(24.6)$ & $211(75.4)$ & \\
\hline 4 & 68.8 & 18.7 & $101(35.4)$ & $184(64.6)$ & \\
\hline 5 & 75.7 & 15.3 & $30(50)$ & $30(50)$ & \\
\hline \multicolumn{6}{|l|}{ Program } \\
\hline Agriculture and environment Sciences & 61.2 & 20.1 & $6(17.6)$ & $28(82.4)$ & $<0.001$ \\
\hline Business and management sciences & 54.1 & 20.1 & $8(8.3)$ & $88(9 \mid .7)$ & \\
\hline Computer and information science & 58.5 & 18.1 & $8(14.3)$ & $48(85.7)$ & \\
\hline Education and external studies & 59.2 & 18.1 & $7(16.7)$ & $35(83.3)$ & \\
\hline Engineering, designing art and technology & 57.0 & 17.9 & $14(8.5)$ & $150(9 \mid .5)$ & \\
\hline Human Sciences/Medicine & 74.2 & 14.2 & $204(43.4)$ & $266(56.6)$ & \\
\hline Humanities and social Sciences & 57.9 & 17.9 & $7(14.3)$ & $42(85.7)$ & \\
\hline Law & 60.4 & 17.0 & $7(12.3)$ & $50(87.7)$ & \\
\hline Veterinary medicine, animal resources. & 62.7 & 19.7 & $8(21.6)$ & $29(78.4)$ & \\
\hline \multicolumn{6}{|l|}{ Region of origin } \\
\hline Central & 69.3 & 18.0 & $125(36.2)$ & $220(63.8)$ & $<0.001$ \\
\hline Eastern & 65.3 & 18.6 & $50(24.8)$ & $152(75.2)$ & \\
\hline Northern & 65.5 & 14.0 & $15(16.7)$ & $75(83.3)$ & \\
\hline Western & 62.1 & 19.4 & $79(21.5)$ & $289(78.5)$ & \\
\hline \multicolumn{6}{|l|}{ Religion } \\
\hline Christianity & 65.7 & 18.3 & $225(26.6)$ & $620(73.4)$ & 0.342 \\
\hline Islam & 64.6 & 18.9 & $37(27.2)$ & $99(72.8)$ & \\
\hline No religion & 66.7 & 25.0 & $7(38.9)$ & II (6I.I) & \\
\hline Traditional African & 57.3 & 19.5 & $0(0)$ & $6(100)$ & \\
\hline \multicolumn{6}{|l|}{ Marital status } \\
\hline Single (never married) & 65.2 & 18.5 & $234(25.6)$ & $679(74.4)$ & 0.061 \\
\hline Married & 70.9 & 16.8 & $22(40)$ & $33(60)$ & \\
\hline Cohabiting & 65.1 & 20.6 & $12(35.3)$ & $22(64.7)$ & \\
\hline Divorced and did not remarry & 64.6 & 15.7 & I (33.3) & $2(66.7)$ & \\
\hline \multicolumn{6}{|l|}{ University } \\
\hline Makerere University & 64.6 & 18.5 & $123(24.8)$ & $372(75.2)$ & $<0.001$ \\
\hline Mbarara University of Science and Technology & 72.2 & 17.6 & $37(4 I .1)$ & $53(58.9)$ & \\
\hline Uganda Christian University & 61.2 & 19.5 & $17(20)$ & $68(80)$ & \\
\hline Kyambogo University & 56.6 & 18.7 & $9(10.8)$ & $74(89.2)$ & \\
\hline Kampala International University & 71.2 & 17.0 & $29(37.2)$ & $49(62.8)$ & \\
\hline Islamic University in Uganda & 70.0 & 16.9 & $19(35.8)$ & $34(64.2)$ & \\
\hline
\end{tabular}


Table 3 (Continued).

\begin{tabular}{|l|l|l|l|l|l|}
\hline \multirow{2}{*}{ Demographics (N=1005) } & \multicolumn{2}{l|}{ Knowledge Score } & \multicolumn{2}{l|}{ Good Knowledge } \\
\cline { 2 - 6 } & Mean & SD & Yes & No & P-value \\
\hline Busitema University & 71.3 & 15.2 & $18(36)$ & $32(64)$ & $24(80)$ \\
Gulu University & 67.9 & 13.7 & $6(20)$ & $22(88)$ & $4(33.3)$ \\
Ndejje University & 57.3 & 19.7 & $3(12)$ & $8(66.7)$ & $4(100)$ \\
St. Augustine International University & 78.6 & 10.1 & 18.7 & $0(0)$ & \\
Uganda Martyrs University & 54.7 & & & \\
\hline
\end{tabular}

Abbreviation: SD, standard deviation.

Table 4 Multivariable Logistic Regression Showing Factors Associated with Good Knowledge of Dementia

\begin{tabular}{|c|c|c|c|}
\hline Demographics & AOR & $95 \% \mathrm{Cl}$ & $\mathbf{P}$ \\
\hline Age & & & \\
\hline 18 to 23 & 1.0 & & \\
\hline$\geq 24$ & 0.9 & $0.6-1.3$ & 0.493 \\
\hline \multicolumn{4}{|l|}{ Year of study } \\
\hline I & 1.0 & & \\
\hline 2 & 1.2 & $0.7-2.2$ & $0.47 I$ \\
\hline 3 & 1.8 & $1.0-3.2$ & 0.035 \\
\hline 4 & 3.1 & I.7-5.4 & $<0.001$ \\
\hline 5 & 4.3 & $2.0-9.4$ & $<0.001$ \\
\hline \multicolumn{4}{|l|}{ Program } \\
\hline Agriculture and environment Sciences & 1.0 & & \\
\hline Business and management sciences & 0.5 & $0.1-1.5$ & 0.200 \\
\hline Computer and information science & 1.0 & $0.3-3.4$ & 0.980 \\
\hline Education and external studies & I.I & $0.3-3.8$ & 0.872 \\
\hline Engineering, designing art and technology & 0.4 & $0.1-1.1$ & 0.086 \\
\hline Human Sciences/Medicine & 3.1 & $1.2-8.0$ & 0.017 \\
\hline Humanities and social Sciences & 0.9 & $0.3-3.0$ & 0.836 \\
\hline Law & 0.5 & $0.2-2.0$ & 0.358 \\
\hline Veterinary medicine, animal resources. & 1.1 & $0.3-3.7$ & 0.898 \\
\hline \multicolumn{4}{|l|}{ Region } \\
\hline Central & 1.0 & & \\
\hline Eastern & 0.5 & $0.3-0.8$ & 0.002 \\
\hline Northern & 0.3 & $0.1-0.5$ & $<0.001$ \\
\hline Western & 0.5 & $0.4-0.8$ & 0.001 \\
\hline \multicolumn{4}{|l|}{ Marital status } \\
\hline Single & 1.0 & & \\
\hline Cohabiting & 1.4 & $0.1-24.4$ & 0.817 \\
\hline Divorced & 0.8 & $0.3-2.2$ & 0.668 \\
\hline Married & 0.6 & $0.3-1.4$ & 0.233 \\
\hline \multicolumn{4}{|l|}{ University } \\
\hline Busitema University & 1.0 & & \\
\hline Gulu University & 0.4 & $0.1-1.3$ & 0.123 \\
\hline Islamic University in Uganda & 0.9 & $0.4-2.2$ & 0.804 \\
\hline Kampala International University & 0.8 & $0.3-1.7$ & 0.529 \\
\hline Kyambogo University & 0.8 & $0.3-2.1$ & 0.610 \\
\hline
\end{tabular}

(Continued) 
Table 4 (Continued).

\begin{tabular}{|l|l|l|l|}
\hline Demographics & AOR & 95\% CI & P \\
\hline Makerere University & 0.8 & $0.4-1.5$ & 0.433 \\
Mbarara University of Science and Technology & 1.3 & $0.6-2.9$ & 0.530 \\
Ndejje University & 0.7 & $0.2-2.9$ & 0.575 \\
St. Augustine International University & 3.4 & $0.8-14.6$ & 0.100 \\
Uganda Christian University & 1.1 & $0.5-2.9$ & 0.783 \\
\hline
\end{tabular}

Abbreviations: $\mathrm{AOR}$, adjusted odds ratio; $\mathrm{Cl}$, confidence interval.

Table 5 Attitudes of Ugandan University Students Towards Dementia

\begin{tabular}{|l|l|l|l|}
\hline Attitude & Yes n (\%) & No n (\%) & I Do Not Know n (\%) \\
\hline Would you share your house with family member who had dementia? & $889(88.5)$ & $53(5.3)$ & $63(6.3)$ \\
Do you believe that people with dementia are responsible for their problem? * & $56(5.6)$ & 89 I (88.7) & $58(5.8)$ \\
Do you see people with dementia as violent and dangerous people to be avoided? * & $72(7.2)$ & $840(83.6)$ & $93(9.3)$ \\
Would you feel ashamed if people knew someone in your family has dementia? * & $42(4.2)$ & $917(91.2)$ & $46(4.6)$ \\
Would you be afraid to have a conversation with someone who has dementia? * & $72(7.2)$ & $889(88.5)$ & $44(4.4)$ \\
Would you be scared having someone with dementia as a neighbor? * & $88(8.8)$ & $872(86.8)$ & $45(4.5)$ \\
Do you think people with dementia can live in the community? & $879(87.5)$ & $80(8)$ & $46(4.6)$ \\
Do you think people with dementia should live in a nursing home? & $487(48.5)$ & $408(40.6)$ & $110(10.9)$ \\
\hline
\end{tabular}

Note: *Scores were reversed while calculating the final attitude score.

Students undertaking health-related programs or were in the senior classes (years three, four, and five) were more likely to have good knowledge of dementia compared to non-medical students. This was consistent with one study where health care students had satisfactory knowledge compared to non-health students. ${ }^{14}$ The possible reason for this difference in knowledge among medical and non-medical may be that dementia education is included in the curricula of health-related programs or interface during the clinical teaching for health-related students as compared to those in nonhealth related programs.

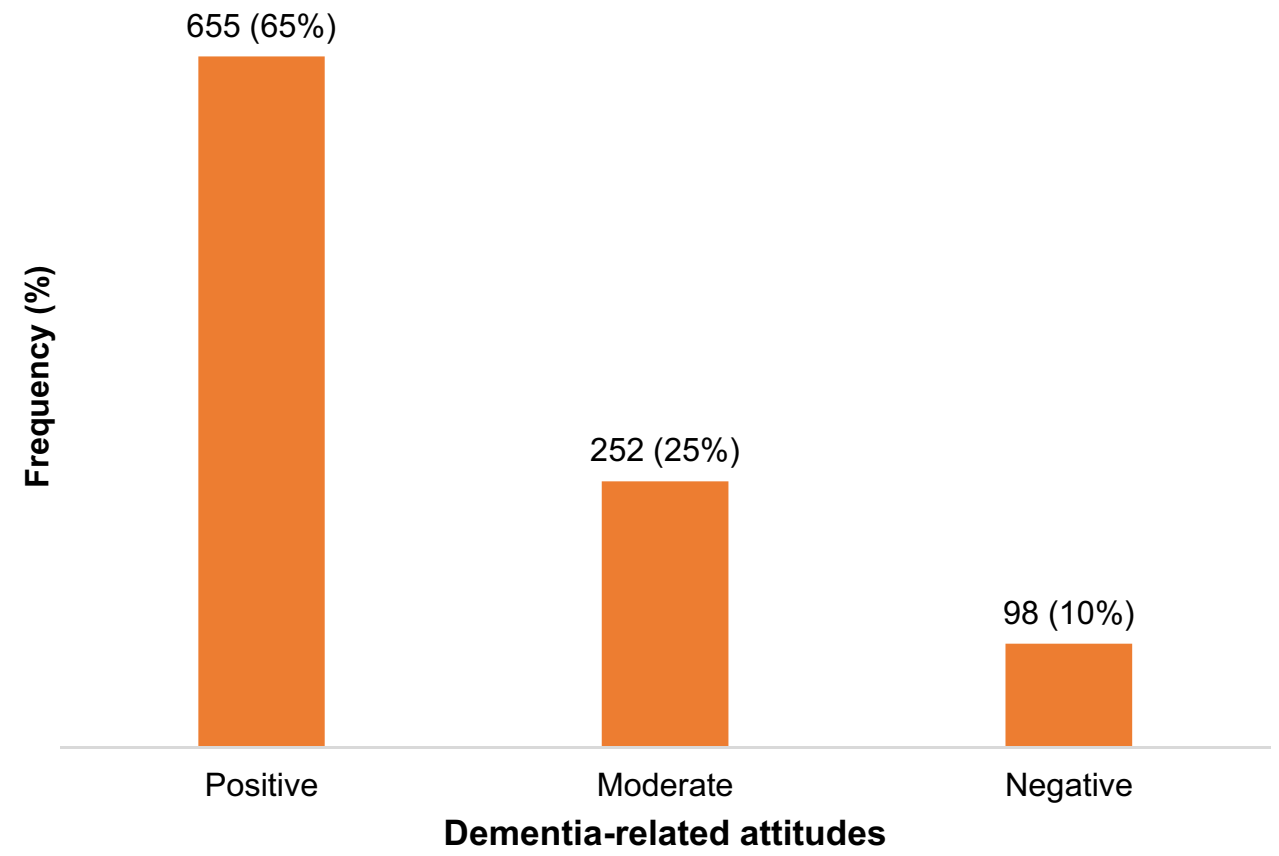

Figure 2 Attitudes towards dementia among Ugandan university students. 
Table 6 Factors Associated with Positive Attitudes Towards Patients with Dementia

\begin{tabular}{|c|c|c|c|c|c|}
\hline \multirow[t]{2}{*}{ Demographics $(N=\mid 005)$} & \multirow[t]{2}{*}{ Mean } & \multirow[t]{2}{*}{ SD } & \multicolumn{3}{|c|}{ Positive Attitude } \\
\hline & & & Yes; n (\%) & No; n (\%) & $\mathbf{P}$ \\
\hline Overall & 81.9 & 19.6 & $655(65.2)$ & $350(34.8)$ & \\
\hline \multicolumn{6}{|l|}{ Sex } \\
\hline Male & 82.8 & 19.0 & $380(66.9)$ & $188(33.1)$ & 0.190 \\
\hline Female & 80.7 & 20.4 & $275(62.9)$ & $162(37.1)$ & \\
\hline \multicolumn{6}{|l|}{ Age; median, IQR } \\
\hline 18 to 23 & 80.4 & 20.0 & $391(61)$ & $250(39)$ & 0.000 \\
\hline$\geq 24$ & 84.5 & 18.7 & $264(72.5)$ & $100(27.5)$ & \\
\hline \multicolumn{6}{|l|}{ Year of study } \\
\hline I & 79.2 & 21.9 & $86(58.9)$ & $60(4 I . I)$ & 0.041 \\
\hline 2 & 82.0 & 17.5 & $146(62.4)$ & $88(37.6)$ & \\
\hline 3 & 80.1 & 22.2 & $182(65)$ & $98(35)$ & \\
\hline 4 & 83.6 & 18.1 & $193(67.7)$ & $92(32.3)$ & \\
\hline 5 & 88.8 & 12.3 & $48(80)$ & $12(20)$ & \\
\hline \multicolumn{6}{|l|}{ Program } \\
\hline Agriculture and environment Sciences & 79.8 & 20.2 & $22(64.7)$ & $12(35.3)$ & 0.006 \\
\hline Business and management sciences & 75.1 & 26.4 & $53(55.2)$ & $43(44.8)$ & \\
\hline Computer and information science & 75.9 & 22.7 & $32(57.1)$ & $24(42.9)$ & \\
\hline Education and external studies & 79.5 & 19.1 & $23(54.8)$ & $19(45.2)$ & \\
\hline Engineering, designing art and technology & 79.1 & 21.8 & $96(58.5)$ & $68(41.5)$ & \\
\hline Human Sciences/Medicine & 85.0 & 16.0 & $330(70.2)$ & $140(29.8)$ & \\
\hline Humanities and social Sciences & 80.4 & 20.9 & $30(61.2)$ & $19(38.8)$ & \\
\hline Law & 86.4 & 15.2 & $45(78.9)$ & $12(21.1)$ & \\
\hline Veterinary medicine, animal resources. & 81.1 & 23.1 & $24(64.9)$ & $13(35.1)$ & \\
\hline \multicolumn{6}{|l|}{ Region of origin } \\
\hline Central & 82.0 & 18.8 & $223(64.6)$ & $122(35.4)$ & 0.194 \\
\hline Eastern & 82.6 & 19.2 & $137(67.8)$ & $65(32.2)$ & \\
\hline Northern & 85.8 & 15.0 & $66(73.3)$ & $24(26.7)$ & \\
\hline Western & 80.4 & 21.4 & $229(62.2)$ & $139(37.8)$ & \\
\hline \multicolumn{6}{|l|}{ Religion } \\
\hline Christianity & 81.7 & 19.8 & $547(64.7)$ & $298(35.3)$ & 0.857 \\
\hline Islam & 83.6 & 18.1 & $91(66.9)$ & $45(33.1)$ & \\
\hline No religion & 77.1 & 24.0 & $12(66.7)$ & $6(33.3)$ & \\
\hline Traditional African & 91.7 & 10.2 & $5(83.3)$ & I (16.7) & \\
\hline \multicolumn{6}{|l|}{ Marital status } \\
\hline Single (never married) & 81.7 & 19.6 & $590(64.6)$ & $323(35.4)$ & 0.665 \\
\hline Married & 85.7 & 18.4 & $40(72.7)$ & $15(27.3)$ & \\
\hline Cohabiting & 80.9 & 23.3 & $23(67.6)$ & II (32.4) & \\
\hline Divorced and did not remarry & 91.7 & 14.4 & $2(66.7)$ & I (33.3) & \\
\hline \multicolumn{6}{|l|}{ University } \\
\hline Makerere University & 81.0 & 19.2 & $315(63.6)$ & $180(36.4)$ & 0.442 \\
\hline Mbarara University of Science and Technology & 84.3 & 17.1 & $62(68.9)$ & $28(3 I . I)$ & \\
\hline Uganda Christian University & 79.9 & 23.6 & $53(62.4)$ & $32(37.6)$ & \\
\hline Kyambogo University & 79.7 & 22.3 & $48(57.8)$ & $35(42.2)$ & \\
\hline Kampala International University & 85.9 & 12.8 & $56(71.8)$ & $22(28.2)$ & \\
\hline Islamic University In Uganda & 86.8 & 18.1 & $40(75.5)$ & $13(24.5)$ & \\
\hline
\end{tabular}


Table 6 (Continued).

\begin{tabular}{|l|l|l|l|l|l|}
\hline Demographics (N=1005) & \multirow{2}{*}{ Mean } & SD & \multicolumn{2}{l|}{ Positive Attitude } \\
\cline { 3 - 6 } & & & Yes; n (\%) & No; n (\%) & P \\
\hline Busitema University & & 20.6 & $35(70)$ & $15(30)$ & $9(30)$ \\
Gulu University & 83.0 & 84.2 & 16.4 & $21(70)$ & $11(44)$ \\
Ndejje University & 79.5 & 26.5 & $14(56)$ & $9(25)$ & $2(50)$ \\
St. Augustine International University & 84.4 & 18.6 & $9(75)$ & $2(50)$ & \\
Uganda Martyrs University & 59.4 & 41.3 & & & 3 \\
\hline
\end{tabular}

In this study, the majority of the participants believed that dementia is a normal part of aging and that memory loss happened to all people as they age. This is the most common misconception in the general public and there is usually a lack of clarity about at which point normal age-

Table 7 Multivariable Logistic Regression Showing Factors Associated with Positive Attitudes Towards Dementia Among Ugandan University Students

\begin{tabular}{|c|c|c|c|}
\hline Demographics & AOR & $95 \% \mathrm{Cl}$ & $\mathbf{P}$ \\
\hline \multicolumn{4}{|l|}{ Sex } \\
\hline Female & 1.0 & & \\
\hline Male & I.I & $0.9-1.5$ & 0.351 \\
\hline \multicolumn{4}{|l|}{ Age } \\
\hline \multicolumn{4}{|l|}{18 to 23} \\
\hline$\geq 24$ & 1.5 & I.I-2.0 & 0.019 \\
\hline \multicolumn{4}{|l|}{ Year of study } \\
\hline 1 & 1.0 & & \\
\hline 2 & 1.2 & $0.8-1.8$ & 0.500 \\
\hline 3 & 1.3 & $0.8-1.9$ & 0.284 \\
\hline 4 & I.I & $0.7-1.8$ & 0.622 \\
\hline 5 & 1.8 & $0.8-3.8$ & 0.144 \\
\hline \multicolumn{4}{|l|}{ Program } \\
\hline Agriculture and environment Sciences & 1.0 & & \\
\hline Business and management sciences & 0.7 & $0.3-1.6$ & 0.390 \\
\hline Computer and information science & 0.7 & $0.3-1.8$ & 0.527 \\
\hline Education and external studies & 0.6 & $0.2-1.6$ & 0.343 \\
\hline Engineering, designing art and technology & 0.8 & $0.4-1.7$ & 0.502 \\
\hline Human Sciences/ Medicine & 1.2 & $0.6-2.6$ & 0.596 \\
\hline Humanities and social Sciences & 0.9 & $0.3-2.2$ & 0.755 \\
\hline Law & 2.3 & $0.9-6.0$ & 0.088 \\
\hline Veterinary medicine, animal resources. & 0.9 & $0.3-2.3$ & 0.753 \\
\hline \multicolumn{4}{|l|}{ Region of origin } \\
\hline Central & 1.0 & & \\
\hline Eastern & I.I & $0.7-1.6$ & 0.694 \\
\hline Northern & 1.4 & $0.8-2.3$ & 0.236 \\
\hline Western & 0.9 & $0.7-1.3$ & 0.722 \\
\hline
\end{tabular}

Abbreviations: $\mathrm{AOR}$, adjusted odds ratio; $\mathrm{Cl}$, confidence interval. related memory loss problems become severe enough to indicate dementia. ${ }^{15}$

About two-thirds of the study respondents had positive attitudes towards people with dementia. This finding is congruent with a greater number of studies reported from Changsha, China, Nigeria, and South Africa. ${ }^{10,16,17}$ Similarly, in our study just like in a cross-sectional study in Changsha, ${ }^{16}$ positive attitudes towards persons with dementia were generally influenced by age. We found a weak correlation between the knowledge and attitude scores although in the vast majority of the studies the attitude score does not correlate with the knowledge score. $^{10,18-20}$

Students play an important role in the dissemination of information to the general public and provide care to patients with dementia. Therefore, efforts to boost the knowledge about the condition among the population should consider students with high regard. This can be done by integrating dementia lectures into the undergraduate academic curricula in the different institutions of learning to improve their knowledge. Additionally, the burden of dementia needs to be better understood in Uganda and other LMICs to enable the allocation of appropriate support and interventions. Consequently, integrating dementia into the academic curriculum along with research done about the condition will increase and maintain knowledge and skills among students and other health professionals. More so, integrating dementia programs into medical and nursing students' curriculum is recommended as nursing research has shown that previous experience of dementia improves students' compassion and care for people affected by dementia. ${ }^{21}$

Undergraduate medical students are the future workforce for patients with dementia, and understanding their attitude and compassion towards dementia patients is important. ${ }^{21}$ Live-model simulations which focus on dementia can help students to become more 
knowledgeable and have better attitudes about dementia and older adults. ${ }^{22}$

\section{Limitations}

Several limitations were taken into consideration as we interpreted these results. First, the study employed a nonrandom sample. Participation in the study was voluntary and no information was available about the characteristics of those who did not participate. Secondly, the crosssectional design of our study does not allow for a causal interpretation of the results. Thirdly, due to the COVID 19 pandemic control measures, all Ugandan universities were temporarily closed, the data collection was only possible via online methods hence missing out on the population that did not own smartphones, poor connectivity to the internet or could not meet the data costs for participating in this study. This could lead to selection bias as students within rural areas might have been missed, this limits the generalization of these findings.

Fourthly, since the questionnaire was selfadministered, there was a possibility of obtaining correct answers without a full understanding of dementia, recall bias and students may have interpreted the questions differently. We also used arbitrary knowledge and attitude scores which might not accurately reflect the knowledge and attitudes of the participants. However, despite these limitations, this is the first study assessing the knowledge and attitude of university students towards dementia in Uganda and SSA.

\section{Conclusion}

Whereas the majority of university students have positive attitudes towards patients with dementia, a significant number still have poor knowledge of dementia. Health education to improve knowledge is encouraged, including incorporation into the academic curriculum dementia sessions. Continuous awareness using the available media is encouraged to improve knowledge not only in this population but also in the general population. Further research into dementia prevalence, causes, and risk factors as well as care-burden and beliefs in Uganda to broaden the understanding of dementia is also urged to enable appropriate support and interventions to be introduced.

\section{Data Sharing Statement}

The data used to support the results of the research are available from the corresponding author upon request.

\section{Ethics Approval and Informed Consent}

Approval for the study was obtained from Mulago Hospital Research and Ethics Committee Reference Number; MHREC-1905. The study was conducted according to the Declaration of Helsinki. All participants were recruited only after informed electronic consent.

\section{Acknowledgments}

The authors appreciate Ms Evelyn Bakengesa, Ms Rhoda, and Ms Regina from HEPI-SHSSU for their support towards funding acquisition. The authors would also like to acknowledge all the University students who responded to the study and the research assistants from different Universities. Makerere University; Edward Tutu, Linda Atulinda, Alvin Akansasira, Lourita Nakyagaba, Arinda Deborah, Angelique Iradukunda. Mbarara University of Science and Technology; Solomon Muwanguzi, Ritah Atukwatsa, Patience Kemigisha. Kyambogo University; Joyce Nakalema, Ivan Kaijuka, Tracy Nalwanga. Gulu university; Simon Kimera, Brian Arube. Busitema University; Rossette Kyarikunda, Kenneth Wandera. Kampala International University (KIU); Obua Jonathan, Wannyana Babrah Iwakuba. Uganda Christian University (UCU); Andrew Okwi, Eria Kalemba, Cajo Delight M. Salamula, Dennis Sengooba Nyanzi, Reagan Muyinda, Tracy Wagonza. Islamic University in Uganda (IUIU); Khadijah Omar, Ndawula Kato Rodney. St. Augustine (King Caesar) International University; Paul Mulyamboga, Dennis Kwizera, and Ndejje University; Ivan Ssempijja, Dorah Namukasa, Amos Tumwesigye.

\section{Author Contributions}

All authors made substantial contributions to conception and design, acquisition of data, or analysis and interpretation of data, took part in drafting the article or revising it critically for important intellectual content, agreed to submit to the current journal, gave final approval to the version to be published, and agree to be accountable for all aspects of the work.

\section{Funding}

This research was supported by the Fogarty International Center of the National Institutes of Health, US Department of State's Office of the US Global AIDS Coordinator and Health Diplomacy (S/GAC), and President's Emergency Plan for AIDS Relief (PEPFAR) under Award Number 
1R25TW011213. The content is solely the responsibility of the authors and does not necessarily represent the official views of the National Institutes of Health.

\section{Disclosure}

Dr Mark Kaddumukasa reports grants from FIC/NINDS; NIH, outside the submitted work. The authors declare no other potential conflicts of interest for this work.

\section{References}

1. World Health Organization. Dementia. 2020. Available from: https:// www.who.int/news-room/fact-sheets/detail/dementia. Accessed May $31,2021$.

2. International D. World Alzheimer report 2019: attitudes to dementia; world Alzheimer report 2019: attitudes to dementia. 2019. Available from: www.daviddesigns.co.uk. Accessed May 31, 2021.

3. Guerchet $M$ et al. Dementia in sub-Saharan Africa: challenges and opportunities; Dementia in sub-Saharan Africa: challenges and opportunities. 2017. Available from: www.leahbeach.com. Accessed May 31, 2021.

4. UNFPA. Population ageing and development 2012. 2012. Available from: https://www.unfpa.org/resources/population-ageing-anddevelopment-2012. Accessed May 31, 2021.

5. Mubangizi V, Maling S, Obua C, Tsai AC. Prevalence and correlates of alzheimer's disease and related dementias in rural Uganda: crosssectional, population-based study. BMC Geriatr. 2020;20:48. doi:10.1186/s12877-020-1461-z

6. Audu IA, Idris SH, Olisah VO, Sheikh TL. Stigmatization of people with mental illness among inhabitants of a rural community in northern Nigeria. Int J Soc Psychiatry. 2013;59:55-60. doi:10.1177/ 0020764011423180

7. Arai Y, Arai A, Zarit SH. What do we know about dementia?: a survey on knowledge about dementia in the general public of Japan. Int J Geriatr Psychiatry. 2008;23:433-438. doi:10.1002/gps.1977

8. Garvey G, Simmonds D, Clements V, et al. Making sense of dementia: understanding amongst indigenous Australians. Int $J$ Geriatr Psychiatry. 2011;26:649-656. doi:10.1002/gps.2578

9. La Fontaine J, Ahuja J, Bradbury NM, Phillips S, Oyebode JR. Understanding dementia amongst people in minority ethnic and cultural groups. $J$ Adv Nurs. 2007;60:605-614. doi:10.1111/j.13652648.2007.04444.x
10. Khonje V, Milligan C, Yako Y, et al. Knowledge, attitudes and beliefs about dementia in an urban xhosa-speaking community in South Africa. Adv Alzheimers Dis. 2015;4(2):21-36. doi:10.4236/ aad.2015.42004

11. Kaliyaperumal K. Guideline for conducting a knowledge, attitude and practice (KAP) study. AECS Illum. 2004;4:7-9.

12. Kada S. Knowledge of alzheimer's disease among Norwegian undergraduate health and social care students: a Survey Study. Educ Gerontol. 2015;41:428-439. doi:10.1080/03601277.2014.982009

13. Baral K, Dahal M, Pradhan S. Knowledge regarding alzheimer's disease among college students of Kathmandu, Nepal. Int J Alzheimers Dis. 2020;2020:1-6. doi:10.1155/2020/6173217

14. Rawlins J. Attitude towards alzheimer's disease among undergraduate students of university of the West Indies, Trinidad and Tobago. J Clin Diagn Res. 2015. doi:10.7860/JCDR/2015/10170.6571

15. Cahill S, Pierce M, Werner P, Darley A, Bobersky A. A systematic review of the public's knowledge and understanding of alzheimer's disease and dementia. Alzheimer Dis Assoc Disord. 2015;29:255-275. doi:10.1097/WAD.0000000000000102

16. Wang Y, Xiao LD, Luo Y, et al. Community health professionals' dementia knowledge, attitudes and care approach: a cross-sectional survey in Changsha, China. BMC Geriatr. 2018;18(1):122. doi:10.1186/s12877-018-0821-4

17. Afolabi AO, Eboiyehi FA, Afolabi KA. Gender analysis of nurses' attitude towards care of the elderly with dementia in Obafemi Awolowo University teaching hospitals complex, ile-ife, Osun State, Nigeria. J Women Aging. 2020;32:203-219. doi:10.1080/ 08952841.2019 .1682488

18. Chertkow H, Feldman HH, Jacova C, Massoud F. Definitions of dementia and predementia states in alzheimer's disease and vascular cognitive impairment: consensus from the Canadian conference on diagnosis of dementia. Alzheimers Res Ther. 2013;5:S2. doi:10.1186/ alzrt198

19. Sheehan B. Assessment scales in dementia. Ther Adv Neurol Disord. 2012;5:349-358. doi:10.1177/1756285612455733

20. Sharma R, Sharma SC, Pradhan SN, Chalise P, Paudel L. Knowledge of alzheimer's disease among medical students of a medical college. J Nepal Med Assoc. 2018;56:666-669. doi:10.31729/jnma.3622

21. Bickford B, Daley S, Sleater G, Hebditch M, Banerjee S. Understanding compassion for people with dementia in medical and nursing students. BMC Med Educ. 2019;19(35). doi:10.1186/s12909019-1460-y

22. Maharaj T. Live-model simulation: improving nursing students' attitudes and knowledge of alzheimer's disease. Clin Simul Nurs. 2017;13:446-451. doi:10.1016/j.ecns.2017.05.002
Advances in Medical Education and Practice

\section{Publish your work in this journal}

Advances in Medical Education and Practice is an international, peerreviewed, open access journal that aims to present and publish research on Medical Education covering medical, dental, nursing and allied health care professional education. The journal covers undergraduate education, postgraduate training and continuing medical education including emerging trends and innovative models linking education, research, and health care services. The manuscript management system is completely online and includes a very quick and fair peer-review system. Visit http://www.dovepress.com/testimonials.php to read real quotes from published authors. 